引用格式: 杨洋, 董锁成, 李泽红. 中蒙俄经济走廊背景下中俄能源合作进展、驱动力、挑战及对策 [J]. 资源科学, 2018,40(2): 237-249. [Yang Y, Dong S C, Li Z H. Progress, driving forces and challenges of Sino-Russian energy cooperation under the ChinaMongolia-Russia economic corridor[J]. Resources Science, 2018,40(2):237-249.] DOI :10.18402/resci.2018.02.02

\title{
中蒙俄经济走廊背景下中俄能源合作进展、 驱动力、挑战及对策
}

\author{
杨 洋 ${ }^{1,2}$, 董锁成 ${ }^{1,2}$, 李泽红 ${ }^{1,2}$
}

(1. 中国科学院地理科学与资源研究所, 北京 $100101 ; 2$. 中国科学院大学, 北京 100049)

摘 要: 中俄能源合作是中俄全面战略协作伙伴关系的重要内容,是意义重大的地缘战略合作。自1996年中 俄能源合作拉开序幕以来, 虽几经波折, 但也取得了较大进展, 且随着中蒙俄经济走廊的规划实施, 中俄能源合作 迎来新机遇。基于此, 本文回顾了中俄能源合作取得的进展, 从供求关系、能源政策、国际劳动地域分工、比较优 势、区域发展政策、国际地缘环境变迁等角度全面分析了中俄能源合作的内在契合因素和外部推动因素,指出中俄 利益诉求的内在契合性是中俄开展能源合作的决定性因素, 外部推动因素则加速了中俄能源合作的进程。虽目前 中俄能源合作态势良好,但仍面临合作体制机制欠缺、国际地缘环境变迁等诸多挑战,在国际地缘环境日益复杂的 新时期, 中俄应增强互信, 深化中俄能源的地缘战略合作; 抓住中蒙俄经济走廊的政策契机,拓宽合作模式与合作 领域; 制定中俄能源战略长期合作规划, 完善中俄能源合作机制; 兼顾周边地区,创建区域性能源共同体。

关键词 :中俄能源合作;进展;驱动力; 挑战;对策; 中蒙俄经济走廊

DOI :10.18402/resci.2018.02.02

\section{1 引言}

中俄能源合作不仅是中俄经贸合作的重要构 成, 同时是中俄全面战略协作伙伴关系的重要内 容, 是保障两国能源安全的地缘战略合作。自 1996 年中俄政府签署“关于共同开展能源领域合作的协 定” 以来 ${ }^{[1,2]}$, 中俄能源合作虽几经波折, 但也取得了 较大进展, 油气贸易量不断增加, 合作领域从单纯 的油气贸易逐渐向包括上游的油气田勘探开发、技 术服务, 中游的油气管道建设及下游的炼油化工合 作等的全产业链合作扩展, 尤其近年来, 随着“一带 一路” 倡议和 “中蒙俄经济走廊” 的规划实施, 中俄 能源合作进展显著。2016年6月, 中蒙俄三国元首 签署《建设中蒙俄经济走廊规划纲要》, 纲要中明确
指出“加强三方在能源矿产资源、高技术、制造业和 农林牧等领域合作” ${ }^{[3]}$, 能源合作作为中俄深化务实 合作的重点领域, 无疑将迎来新的发展机遇。2017 年 5 月, 中俄原油管道累计输油量超过 1 亿 $\mathrm{t}$, 中俄能 源合作步人快车道。然而,虽然目前中俄能源合作 态势良好,但仍面临着合作体制机制欠缺、国际地 缘环境变迁等诸多挑战, 亟需理清新时期中俄能源 合作的驱动力和面临的挑战,制定针对性的对策措 施, 抓住中蒙俄经济走廊建设带来的新机遇, 不断 深化中俄能源合作。

目前关于中俄能源合作的研究主要集中在两 方面。(1)中俄能源合作态势研究。孙龙德等、郝宇 彪等、徐洪峰等分别对苏联解体以来, 中俄能源合

收稿日期: 2017-04-11, 修订日期: 2017-09-16

基金项目:国家科技基础资源调查专项子课题(2017FY101304); 国家社会科学基金项目(17VDL016); 中国科学院重点部署项目子课题 (ZDRW-ZS-2016-6-5)。

作者简介:杨洋,女,河南新乡人,博士生,主要研究领域为资源经济和环境经济。E-mail: feiyang199012@163.com 通讯作者 :董锁成,E-mail: dongsc3@163.com 
作取得的进展进行了回顾与总结 ${ }^{[1,2,4]}$; 陈小沁、陈宪 良、郭锐等、张恒龙等、王海运分别对中俄能源合作 的现状、问题及对策进行了分析, 指出俄罗斯对中 俄能源合作的地缘政治影响的顾虑是制约中俄能 源合作的主要因素, 中俄应加强政治互信, 制定中 俄长期能源合作战略 ${ }^{[5-9]}$ 。(2)俄罗斯能源政策和能 源战略研究。郎一环等对俄罗斯能源地缘政治战 略和中俄能源合作前景进行了分析, 提出了促进中 俄能源合作的对策 ${ }^{[10]}$; 方婷婷分析对比了不同阶段 俄罗斯对外能源战略的演变,得出现阶段俄罗斯的 能源政策更加灵活和务实, 俄罗斯不仅要通过能源 来壮大自身经济实力, 还要通过 “能源武器” 来提升 自己的大国地位 ${ }^{[11,12]}$ 。陈小沁、王晓梅分别对《2030 年前俄罗斯能源战略》和《2035 年前俄罗斯能源战 略草案》进行了解析, 指出中俄能源合作具有较大 潜力 ${ }^{[1,14]}$ 。

现有研究对促进中俄能源合作具有重要的指 导意义, 然而, 随着中蒙俄经济走廊的规划实施以 及国际地缘环境的变迁, 中俄能源合作步人新阶 段, 现有研究难以满足新阶段、新形式下深化中俄 能源合作的需求。此外,已有研究主要从地缘政治 角度分析中俄能源合作的问题与挑战, 对中俄能源 合作的驱动力、能源合作的战略意义及经济意义分 析不足。因此, 本文立足于中蒙俄经济走廊建设的 新时期, 首先回顾了中俄能源合作的进展, 其次从 供求关系、能源政策、国际劳动地域分工、比较优
势、区域发展政策、国际地缘环境变迁等角度全面 分析了新时期中俄能源合作的驱动力, 剖析了中俄 能源合作面临的挑战,最后,在理论分析的基础上 提出了针对性的对策, 将为新时期深化中俄能源合 作提供重要的科学支撑和理论指导。

\section{2 中俄能源合作进展}

自 1996年中俄能源合作拉开序幕以来,中俄能 源合作取得了较大进展,一方面,油气贸易日益紧密, 另一方面合作领域由单纯的油气贸易向包括上游的 油气田勘探开发、技术服务, 中游的油气管道建设 及下游的炼油化工合作等的全产业链合作扩展。

\section{1 中俄油气贸易进展}

\subsection{1 石油贸易进展}

1996-2015年,中俄石油贸易量逐渐上升,中国 从俄罗斯进口的石油量从 31.9 万 $\mathrm{t}$ 增加至 4243.2 万 $\mathrm{t}$ （详见图 1）。2015 年,俄罗斯成为中国的第二大石 油进口来源国, 中国从俄罗斯进口的石油量占中国 石油进口总量的 $12.7 \%$ (详见图 2), 中国亦成为俄罗 斯的第二大石油出口对象国,俄罗斯出口到中国的 石油量占俄罗斯石油出口总量的 15.8\%(详见图 3), 中俄石油贸易进展显著。期间, 中俄签署了若干重 要协议与合同推动中俄石油合作 (详见表 1 , 见第 240 页)。在中俄政府的推动下, 中俄原油管道全线 于 2011 年 1 月 1 日正式运营,实现了输送方式由铁 路运输向 “管道运输为主、铁路运输为辅” 的转变, 被誉为中俄“能源合作新的里程碑”,开启了中俄能 源合作的新时代。

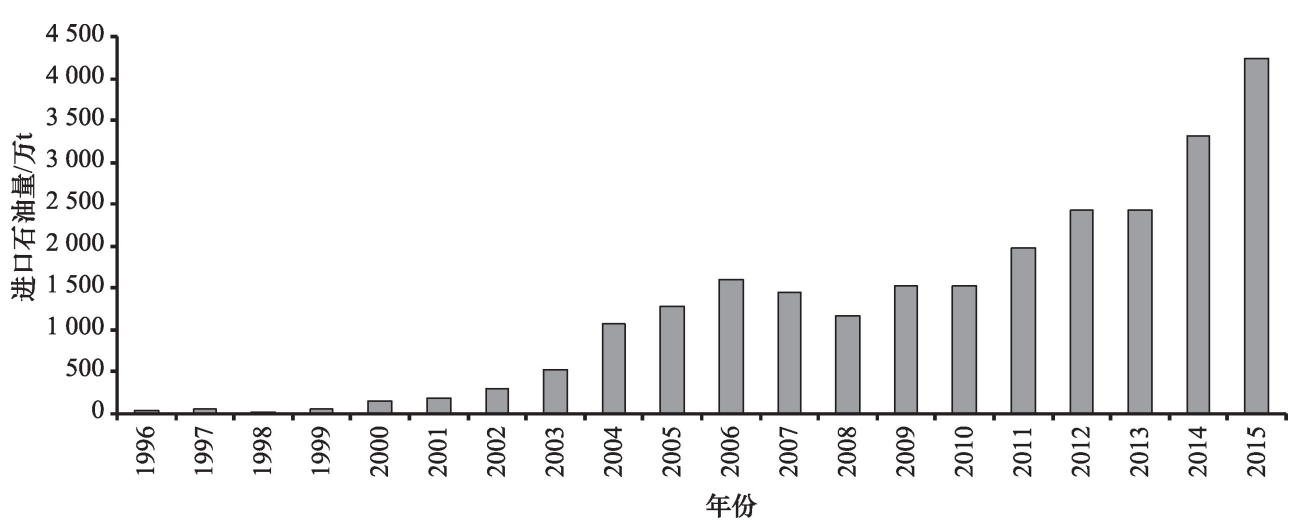

图 $11996-2015$ 年中国从俄罗斯进口的石油量

Figure 1 The volume of oil that china imported from Russia from 1996 to 2015 数据来源: UN Comtrade Database ${ }^{[15]}$ 。 


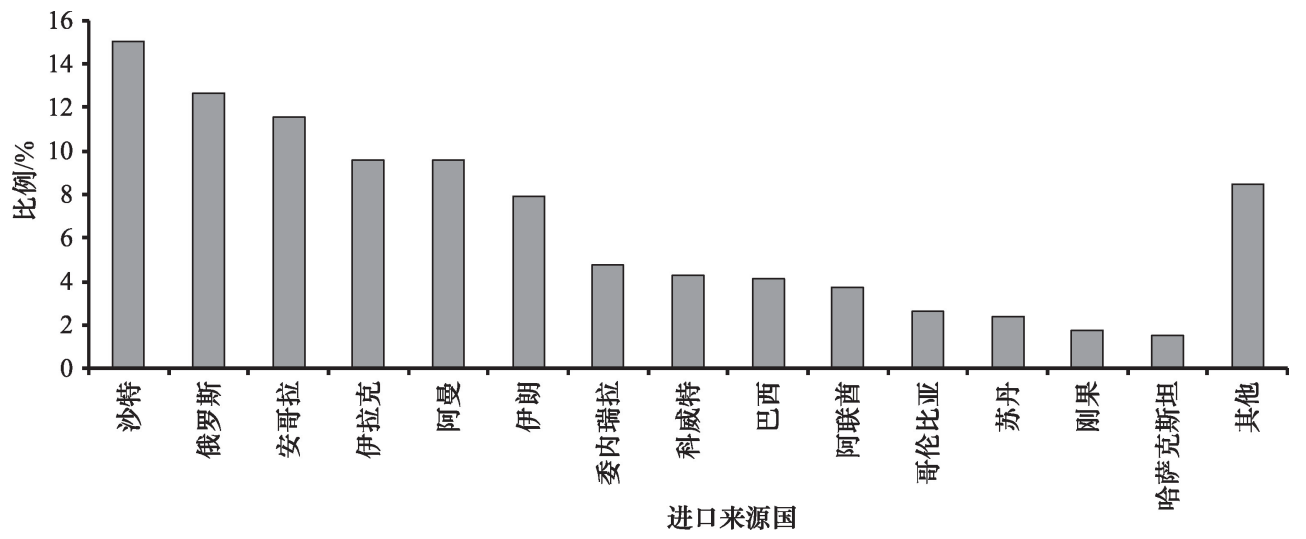

图 22015 年中国从各石油进口来源国进口的石油量占中国石油进口总量的比例

Figure 2 The share of different source countries in China's total oil import in 2015 数据来源: UN Comtrade Database ${ }^{[15]}$ 。

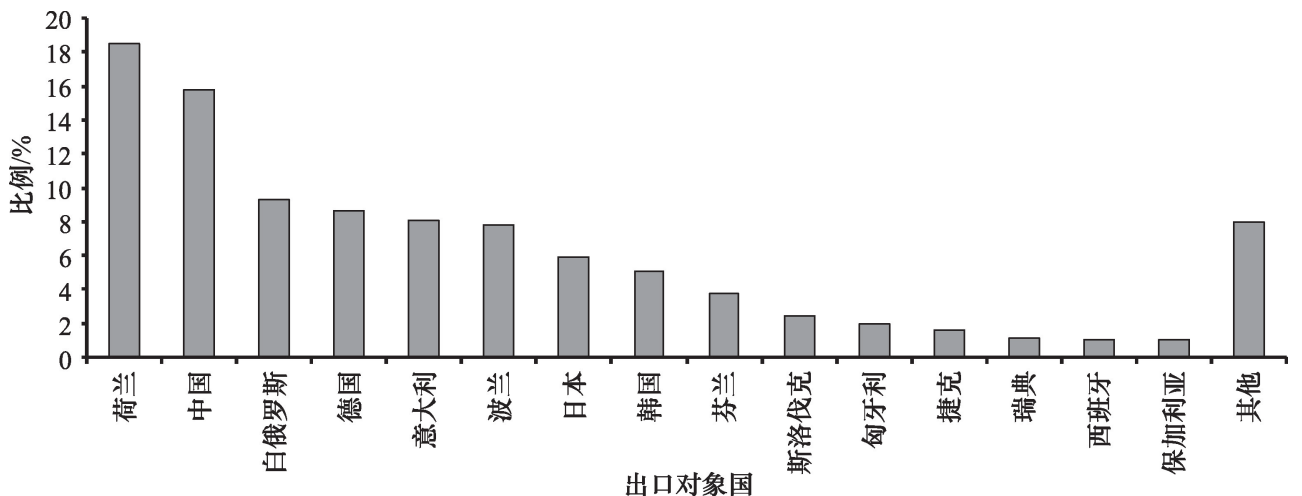

图 32015 年俄罗斯向各石油出口对象国出口的石油量占俄罗斯石油出口总量的比例

Figure 3 The share of different market countries in Russia's total oil export in 2015 数据来源: UN Comtrade Database ${ }^{[15]}$ 。

\subsection{2 天然气贸易进展}

自中俄开展能源合作以来, 中俄双方便开始洽 谈天然气合作, 但直至 2009 年, 天然气贸易才逐渐 展开, 但数量十分有限。2009-2015 年间, 中俄天 然气贸易量在 10 万 40 万 $\mathrm{t}$ 波动 (详见图 4)。2015 年, 中国从俄罗斯进口的天然气仅为 19.9 万 $\mathrm{t}$, 占中 国天然气进口总量的 $0.4 \%$, 占俄罗斯天然气出口总 量的 $0.2 \%{ }^{[15]}$ 。中国进口的天然气中 $80 \%$ 左右来自 于亚洲地区 (详见图 5, 见第 241 页), 俄罗斯出口的 天然气中将近 $80 \%$ 出口到欧洲地区 (详见图 6, 见第 241)。然而, 在两国政府的推动和国际地缘环境的 影响下, 2013 年以来, 中俄在天然气合作领域取得 了重大突破。2014年 1 月, 中石油成功人股诺瓦泰 克公司旗下亚马尔液化天然气公司, 与诺瓦泰克公 司、法国道尔达石油公司共同开发俄罗斯北极亚马
尔液化天然气 $(\mathrm{LNG})$ 项目; 2014 年 5 月,中石油与俄 罗斯天然气工业股份公司 (以下简称俄气) 签订《中 俄东线供气购销合同》, 商定建设中俄东线天然气 管道 ${ }^{[2]} ; 2014$ 年 11 月,中石油和俄气再签《关于沿西 线管道从俄罗斯向中国供应天然气的框架协议 $\rangle^{(23]}$ （详见表1）, 中俄天然气合作步人快车道。

\section{2 中俄油气全产业链合作进展}

近年来,在中国“走出去”战略的推动下,中国 企业逐渐以持股、合资建厂、并购等方式参与到俄 罗斯油气资源勘探开发中,中俄在油气全产业链合 作上取得较大进展,主要包括上游的油气田勘探开 发与工程技术服务,中游的油气管道建设以及下游 的炼油化工合作。

2.2.1 上游的油气田勘探开发与工程技术服务合作 中石油和中石化是中国最早进人到俄罗斯能 


\section{表 1 中俄能源合作重要协议与合同}

Table 1 Main Sino-Russian agreements or contracts of energy cooperation

\begin{tabular}{|c|c|c|c|c|c|}
\hline 合作类别 & 时间 & 中方 & 俄方 & 协议或合同 & 主要内容 \\
\hline \multirow[t]{7}{*}{$\begin{array}{l}\text { 石油 } \\
\text { 合作 }\end{array}$} & 1996年4月 & 中国政府 & 俄政府 & $\begin{array}{l}\text { 关于共同开展能源领域合作 } \\
\text { 的协定 }\end{array}$ & $\begin{array}{l}\text { 双方将开展从俄罗斯东西伯利亚地区向中国供气、 } \\
\text { 供油及经中国过境转运给第三国的输送天然气管道 } \\
\text { 或输送原油管道的共同研究 }\end{array}$ \\
\hline & 2005 年 1 月 & 中石油 & 俄石油 & $\begin{array}{l}\text { 《关于进口 } 4840 \text { 万吨俄罗斯 } \\
\text { 原油的长期贸易合同》 }{ }^{[16]}\end{array}$ & $\begin{array}{l}\text { 俄罗斯 } 2005-2010 \text { 年向中国供油 } 4840 \text { 万 t, 并从中 } \\
\text { 国贷款 } 60 \text { 亿美元。 }\end{array}$ \\
\hline & 2005年7月 & 中石油 & 俄石油 & 《长期合作协议》》 ${ }^{[17]}$ & 确定了在油气领域实现优势互补、共同发展的原则 \\
\hline & 2006年3月 & 中石油 & 俄石油 & $\begin{array}{l}\text { 《俄罗斯境内开展石油资源 } \\
\text { 勘探开发合作和在中国境内 } \\
\text { 开展炼油加工和销售一体化 } \\
\text { 合作的原则协议》17] }\end{array}$ & $\begin{array}{l}\text { 将在俄罗斯境内开展石油资源勘探开发合作,在中 } \\
\text { 国境内开展炼油加工和销售一体化合作 }\end{array}$ \\
\hline & 2009年4月 & 中国政府 & 俄政府 & $\begin{array}{l}\text { 中俄石油领域合作政府间 } \\
\text { 协议 }\end{array}$ & $\begin{array}{l}\text { 授权中石油和俄罗斯国家石油管道运输公司共同建 } \\
\text { 设中俄原油管道,并且签署了 } 250 \text { 亿美元贷款项下, } \\
\text { 俄罗斯从 } 2011 \text { 年开始每年通过管道向中国供应 } \\
1500 \text { 万 } \mathrm{t} \text { 为期 } 20 \text { 年的长期原油管道贸易合同 }\end{array}$ \\
\hline & 2013 年 6 月 & 中石油 & 俄石油 & $\begin{array}{l}\text { 《预付款条件下俄罗斯向中 } \\
\text { 国增供原油的购销合同》|[19] }\end{array}$ & $\begin{array}{l}\text { 俄石油在中俄原油管道每年 } 1500 \text { 万 } \mathrm{t} \text { 的基础上逐年 } \\
\text { 向中国增供原油, 到 } 2018 \text { 年达到每年 } 3000 \text { 万 } \mathrm{t} \text {, 为期 } \\
25 \text { 年 (可延长 } 5 \text { 年), 中哈原油管道自 } 2014 \text { 年开始每 } \\
\text { 年增供原油 } 700 \text { 万 } \mathrm{t} \text {, 为期 } 5 \text { 年 }{ }^{[4]}\end{array}$ \\
\hline & 2013 年 10 月 & 中石化 & 俄石油 & 《预付款出口合同备忘录》〉[20] & $\begin{array}{l}\text { 从 } 2014 \text { 年起俄石油每年向中石化供应原油 } 1000 \text { 万 } \mathrm{t} \text {, } \\
\text { 为期 } 10 \text { 年 }\end{array}$ \\
\hline \multirow[t]{3}{*}{$\begin{array}{l}\text { 天然气 } \\
\text { 合作 }\end{array}$} & 2013年 10 月 & 中石油 & $\begin{array}{l}\text { 诺瓦泰克 } \\
\text { 公司 }\end{array}$ & $\begin{array}{l}\text { 《亚马尔公司液化天然气 } \\
(\mathrm{LNG}) \text { 购销框架协议》 }{ }^{[21]}\end{array}$ & $\begin{array}{l}\text { 签署每年不低于 } 300 \text { 万 } \mathrm{t} \text { 的 } \mathrm{LNG} \text { 进口协议, 合同期为 } \\
15 \text { 年 }\end{array}$ \\
\hline & 2014年 5 月 & 中石油 & 俄气 & 《中俄东线供气购销合同》|[22] & $\begin{array}{l}\text { 建设中俄东线天然气管道, 预计在 } 2018 \text { 年建成投产, } \\
\text { 达产后年供气量将达到 } 380 \text { 亿 } \mathrm{m}^{3} \text {, 为期 } 30 \text { 年 }\end{array}$ \\
\hline & 2014年11月 & 中石油 & 俄气 & $\begin{array}{l}\text { 《关于沿西线管道从俄罗斯 } \\
\text { 向中国供应天然气的框架协 } \\
\text { 议》 }\end{array}$ & $\begin{array}{l}\text { 中俄西线天然气管道的供气规模未来将达到每年 } \\
300 \text { 亿 } \mathrm{m}^{3}\end{array}$ \\
\hline
\end{tabular}

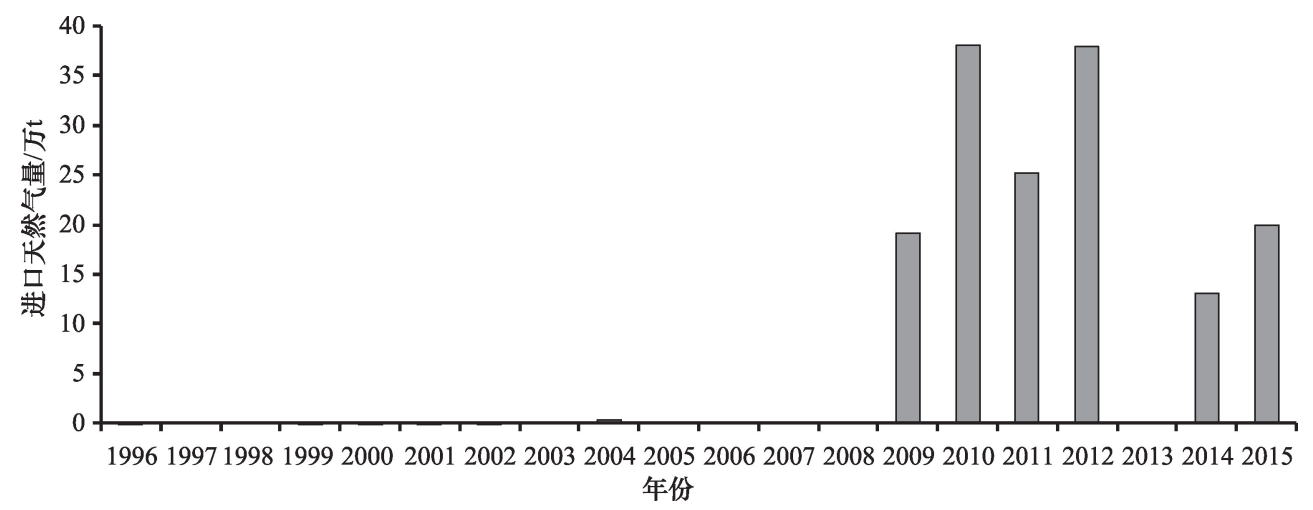

图 4 1996-2015 年中国从俄罗斯进口的天然气量

Figure 4 The volume of gas that china imported from Russia from 1996 to 2015 数据来源: UN Comtrade Database ${ }^{[15]}$ 。

源勘探开发市场的企业,也是与俄罗斯能源企业合 作最密切的中方企业。2003年12月,中石油与俄罗 斯萨哈林石油股份有限公司 (以下简称萨哈林石
油)签订“萨哈林油田的勘探开发框架协议”,拉开 了中俄油气上游合作的序幕 ${ }^{[4]} ; 2005$ 年 7 月, 中石化 与萨哈林石油签订“有关建立合资企业共同参与俄 


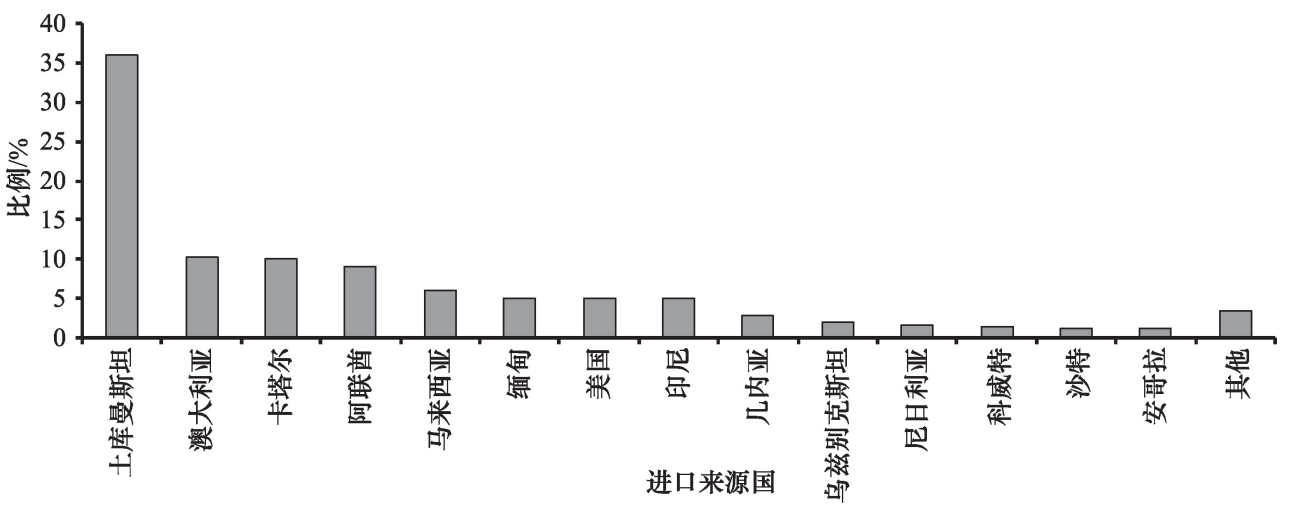

图 52015 年中国从各天然气进口来源国进口的天然气量占中国天然气进口总量的比例

Figure 5 The share of different source countries in China's total gas import in 2015 数据来源: UN Comtrade Database $\mathrm{e}^{[1]]}$

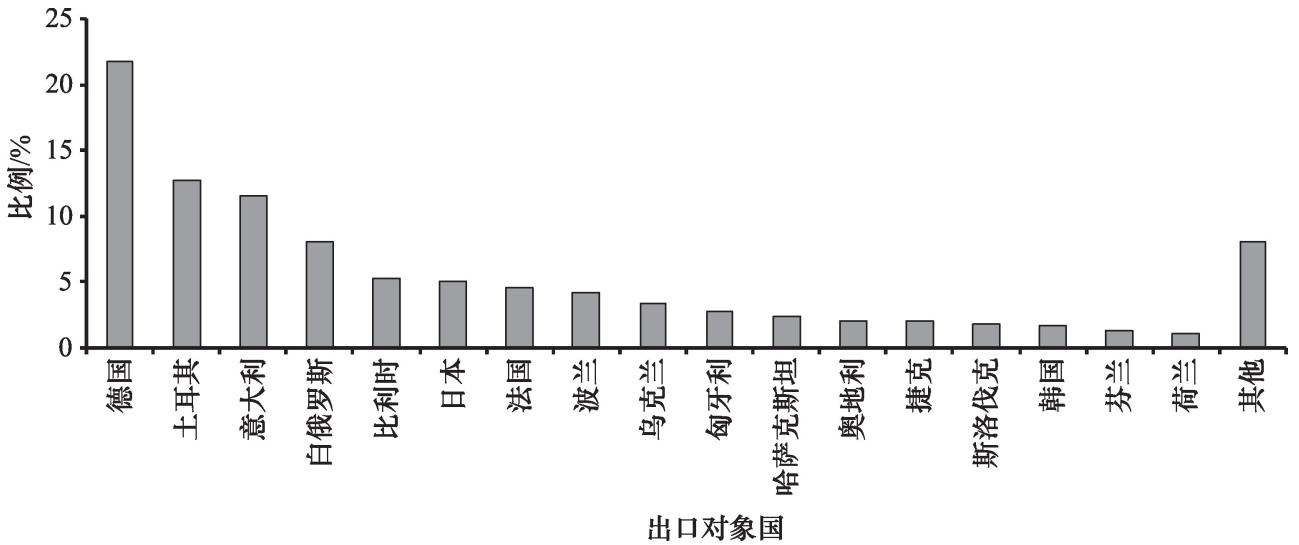

图 62015 年俄罗斯向各天然气出口对象国出口的天然气量占天然气出口总量的比例

Figure 6 The share of different market countries in Russia's total gas export in 2015 数据来源:BP Statistical Review of World Energy $2016^{[25]}$ 。

罗斯远东 “萨哈林-3 号” 油气田开发的协议”, 获得 萨哈林-3油气田 $25 \%$ 的股份 ${ }^{[1]} ; 2006$ 年 10 月, 中石油 与俄罗斯石油公司 (以下简称俄石油) 合资成立东 方能源公司, 中方持股 $49 \%$, 俄方持股 $51 \%{ }^{[4]}$ 。此 后,中石油、中石化、中海油、丝路基金、北京市燃气 集团有限责任公司等企业相继加人到俄罗斯油气 田勘探开发中(详见表 2)。油气田勘探开发合作带 动了工程技术服务方面的合作, 加快了中国制造 业、工程技术服务走向世界的步伐。2006年6月,中 石油获得秋明-英国石油公司的三维地震采集项 目, 2010 年 5 月,中石油与俄罗斯地球物理 $(\mathrm{TNG})$ 测 井公司签订了 MCI5570 微电阻率扫描仪器销售及 技术服务合同,实现了中国该类仪器在俄罗斯市场 的零突破; 2014 年 7 月, 中海油参与亚马尔 LNG 项
目 264 个核心工艺模块建造, 中国制造、中国工程技 术服务逐渐走向世界 ${ }^{[4]}$ 。

\subsection{2 中游的油气管道建设合作}

2009年,中俄政府签订协议授权中石油和俄罗 斯国家石油管道运输公司共同建设中俄原油管道, 该管道于 2010 年 9 月 27 日全线竣工,于 2011 年 1 月 1 日全线正式运营,成为中俄“能源合作新的里程 碑”,开启了中俄能源合作的新阶段。2014年 5月,中 石油与俄气签署《中俄东线供气购销合同》, 商定建 设中俄东线天然气管道,俄罗斯段和中国段已分别 于 2014 年 9 月和 2015 年 6 月开工建设,预计在 2018 年建成投产,达产后年供气量将达到 380 亿 $\mathrm{m}^{3[22]}$; 同 年 11 月,中俄签署《关于沿西线管道从俄罗斯向中 国供应天然气的框架协议 $\rangle^{[23]}$, 但由于双方在天然气 价格方面存在分歧,西线管道建设仍在商谈中。 
表 2 中俄油气全产业链合作项目

Table 2 Projects of Sino Russian oil and gas whole industry chain cooperation

\begin{tabular}{|c|c|c|c|c|}
\hline 合作领域 & 时间 & 中方 & 俄方 & 合作内容 \\
\hline \multirow[t]{11}{*}{ 上游合作 } & 2003 年 12 月 & 中石油 & 萨哈林石油 & 签订“萨哈林油田勘探开发框架协议” \\
\hline & 2005 年 7 月 & 中石化 & 萨哈林石油 & $\begin{array}{l}\text { 签订有关建立合资企业共同参与俄罗斯远东“萨哈林-3号”油气 } \\
\text { 田开发的协议,获得萨哈林-3 油气田 } 25 \% \text { 的股份 }\end{array}$ \\
\hline & 2006年6月 & 中石化 & $\begin{array}{l}\text { 俄罗斯乌德穆尔特石 } \\
\text { 油公司 }\end{array}$ & 乌德穆尔特项目, 中方持股 49\%, 俄方持股 51\% \\
\hline & 2006年10月 & 中石油 & 俄石油 & 合资成立东方能源公司, 中方持股 $49 \%$, 俄方持股 $51 \%$ \\
\hline & 2014年1月 & 中石油 & 诺瓦泰克公司 & $\begin{array}{l}\text { 亚马尔 LNG 项目, 中石油持股 } 20 \% \text {, 诺瓦泰克公司持股 } 50.1 \% \text {, } \\
\text { 道达尔持股 } 20 \%\end{array}$ \\
\hline & 2015 年9月 & 中石化 & 俄石油 & $\begin{array}{l}\text { 签订“共同开发鲁斯科耶油气田和尤鲁勃切诺一托霍姆油气田 } \\
\text { 合作框架协议” }\end{array}$ \\
\hline & 2015 年9月 & 丝路基金 & 诺瓦泰克公司 & 亚马尔 LNG项目,丝路基金持股 $9.9 \%$ \\
\hline & 2016年11月 & $\begin{array}{l}\text { 北京市燃气集团 } \\
\text { 有限责任公司 }\end{array}$ & 俄石油 & 向中国公司出售上琼斯克石油天然气公司 20\%的股份 \\
\hline & 2006年6月 & 中石油 & 秋明-英国石油公司 & 三维地震采集项目 \\
\hline & 2010 年 5 月 & 中石油 & $\begin{array}{l}\text { 俄罗斯地球物理测井 } \\
\text { 公司 }\end{array}$ & MCI5570微电阻率扫描仪器销售及技术服务合同 \\
\hline & 2014年7月 & 中海油 & 诺瓦泰克公司 & 参与亚马尔 LNG 项目 264 个核心工艺模块建造 \\
\hline \multirow[t]{2}{*}{ 中游合作 } & 2009年4月 & 中石油 & $\begin{array}{l}\text { 俄罗斯国家石油管道 } \\
\text { 运输公司 }\end{array}$ & 建设中俄原油管道,于 2011年1月 1 日全线正式运营 \\
\hline & 2014年 5 月 & 中石油 & 俄气 & $\begin{array}{l}\text { 中俄东线天然气管道,俄罗斯段于 } 2014 \text { 年 } 9 \text { 月开工建设,中国段 } \\
\text { 于 } 2015 \text { 年 } 6 \text { 月开工建设 }\end{array}$ \\
\hline \multirow[t]{4}{*}{ 下游合作 } & 2007年 10 月 & 中石油 & 俄石油 & 中俄东方石化 (天津)有限公司, 中方持股 $51 \%$, 俄方持股 $49 \%$ \\
\hline & 2013 年 8 月 & 中石化 & 西布尔 & $\begin{array}{l}\text { 合资成立俄罗斯克拉斯诺亚尔斯克市合成橡胶厂, 中方认购 } 25 \% \\
\text { 股份 }+1 \text { 股并参与管理 }\end{array}$ \\
\hline & 2014年 5月 & 中石化 & 西布尔 & $\begin{array}{l}\text { 在上海合资成立年产量 } 5 \text { 万 } \mathrm{t} \text { 的丁腈橡胶工厂, 中石化持股 } \\
74.9 \% \text {,西布尔持股 } 25.1 \%\end{array}$ \\
\hline & 2015年12月 & 中石化 & 西布尔 & 中石化收购西布尔 $10 \%$ 股权的交易完成交割 \\
\hline
\end{tabular}

\subsection{3 下游的炼油化工合作}

在炼油化工合作方面, 2007 年 11 月, 中石油与 俄石油在中国天津成立合资公司“中俄东方石化 (天津) 有限公司”, 中方持股 $51 \%$, 俄方持股 $49 \%$; 2011 年 10 月, 中石化与俄罗斯西布尔公司 (以下简 称西布尔)签署合作备忘录, 商定分别在中国和俄 罗斯设立两个合资公司生产丁腈橡胶, 并考虑在异 戊橡胶及其他领域开展合作; 2013 年 8 月,中石化与 西布尔签署了“关于克拉斯诺亚尔斯克市合成橡胶 厂股份公司股东协议”, 认购该橡胶厂 $25 \%$ 股份 +1 股并参与管理; 2014 年 5 月, 双方协定在上海合资成 立年产量 5 万 $\mathrm{t}$ 的丁腈橡胶工厂, 中方持股 $74.9 \%$, 俄方持股 $25.1 \%^{[1,4]} ; 2015$ 年 12 月, 中石化收购西布 尔 $10 \%$ 的股份交易完成交割 ${ }^{[26]}$ 。

\section{3 中俄能源合作的驱动力与挑战}

\section{1 中俄能源合作的驱动力}

1996 年至今, 中俄能源合作取得了较大进展,
这一方面取决于中俄利益诉求的内在契合性, 另一 方面得益于国际地缘环境、能源战略变迁等外部因 素的推动。能源合作作为中俄的地缘战略合作, 加 强能源合作既符合两国发展的战略需求, 又符合经 济发展原则,具有重要的战略意义和经济意义。下 文分别从能源供求关系、能源政策、国际劳动地域 分工、比较优势、区域发展政策以及国际地缘环境 等角度对中俄能源合作的内在契合因素和外部推 动因素进行分析。

\subsection{1 中俄能源合作的内在契合因素}

(1)中俄能源供求互补是根本, 为能源合作奠 定了基础。目前, 中国已成为世界第一大能源消费 国和石油净进口国, 能源供需缺口巨大。2015 年, 中国石油消费量达到 5.4 亿t, 对外依存度首次突破 $60 \%$, 天然气消费量达到 1910 亿 $\mathrm{m}^{3}$, 对外依存度超 过 32\% 。同时, 中国正处在快速工业化和城镇化 进程中, 能源需求在短期内仍将保持增长态势。然 
而, 中国能源结构滞后, 2015 年, 中国的一次能源结 构中煤炭占到 $64.0 \%$, 是世界平均水平的 2 倍多, 而 天然气仅占 $5.9 \%$, 仅为世界平均水平的 $1 / 4$, 在环境 问题的倒逼下, 中国对石油、天然气等较清洁能源 的需求将持续扩大。据美国能源信息署预测, 以中国 为主的新兴经济体将成为未来石油消费增长的主 体 ${ }^{[28]}$ 。此外, 中国发布的《能源发展战略行动计划 （2014-2020)》中已将天然气列为煤炭的重要替代 能源, 计划到 2020 年, 天然气的消费比例增加至 $10 \%$, 并且把加强与俄罗斯的能源合作作为实现这 一目标的重要选择 ${ }^{[29]}$ 。俄罗斯是能源大国和能源出 口国, 2015 年,俄罗斯石油出口量达到 2.4 亿 $\mathrm{t}$, 天然 气出口量达到 9902.6 万 $\mathrm{t}$, 是世界第二大石油出口国 和天然气出口国 ${ }^{[15]}$, 然而, 2015 年俄罗斯出口到中 国的石油量不足 5000 万 $\mathrm{t}$, 天然气出口量不足 20 万 $\mathrm{t}$ 。 从供求关系和贸易现状来看, 中俄能源供求高度 互补,未来中俄油气合作, 尤其是天然气合作潜力 巨大。

(2) 中俄能源政策高度契合, 有助于保障两国 能源安全。能源进口多元化战略和能源出口多元 化战略分别是中俄两国保障能源安全的重要战 略。就中国而言, 中国进口的石油中将近 $60 \%$ 从中 东和西非进口, 天然气进口中, $80 \%$ 左右从土库曼斯 坦、澳大利亚、卡塔尔等亚洲国家进口。俄罗斯出 口的油气资源中 $60 \%$ 以上的石油、将近 $80 \%$ 的天然 气出口到欧洲地区。中国油气进口来源与俄罗斯 油气出口对象的高度集中成为制约两国能源安全 的重要潜在风险因素。中国在其《能源发展战略行 动计划(2014-2020年)》中指出要加强同俄罗斯的 能源合作区域建设,建立区域性能源交易市场 ${ }^{[29]}$ 。 俄罗斯在其《2030 年前能源战略》、《2035 年前能源 战略草案》中多次强调亚太市场的重要性, 其《2030 年前能源战略》指出要实现能源出口市场和产品出 口结构的多元化,保持俄与传统能源国稳定关系的同 时, 与新兴能源市场建立同样稳定的合作关系 ${ }^{[30]}$; 其 《2035 年前俄罗斯能源战略草案》中明确提出到 2034 年俄出口到亚太地区的原油份额从目前的 $12 \%$ 提高 到 $32 \%$, 天然气从目前的 $6 \%$ 提高到 $31 \%^{[31]}$, 中国凭借 其在油气消费市场的重要地位成为俄 “东进” 的优 先选择。中俄能源政策、能源战略高度契合, 中俄
能源合作将降低其他国家或地区对本国能源安全 的牵制, 有助于保障两国的能源安全。

(3) 中俄国际劳动地域分工、比较优势互补性 强,有利于提高两国效益。中国是制造业大国,制 造业占 GDP 的 $36 \%$, 是全球制造业竞争力最强的国 家 ${ }^{[32]}$, 但中国能源资源相对匮乏。俄罗斯制造业发 展滞后,但俄罗斯丰富的能源资源决定了其在世界 舞台的地位,能源产业成为俄罗斯的支柱产业。据统 计,俄罗斯能源部门的产值占国民经济总产值的 1/4, 占全国工业总产值的 $1 / 3$, 其收人占联邦财政收人 的近一半, 能源出口创汇额也占到了全国的一半 ${ }^{[1]}$ 。 中俄产业结构差异明显, 比较优势高度互补。根据 国际劳动地域分工理论和比较优势理论,每个国家 都应该生产并出口其具有“比较优势”的产品,进口 其具有“比较劣势”的产品, 以获得更大的经济、社 会、生态效益。因此俄罗斯应生产并向中国出口其 能源产品, 中国应向俄罗斯出口其制造业产品, 通 过分工合作、优势互补，提高两国的经济、社会、生 态效益。

（4）中俄区域发展政策为中俄能源合作带来新 机遇。2013 年, 中国启动“一带一路”倡议, 旨在实 现“一带一路”沿线国家“政策沟通、道路联通、贸易 畅通、货币流通和民心相通”; 2015 年 1 月 1 日, 俄罗 斯倡导的欧亚经济联盟正式启动, 旨在实现联盟国 家商品、服务、资本和劳动力的自由流动, 与中国 “一带一路”倡议高度契合。为此, 中俄双方积极对 接, 于 2015 年 5 月在莫斯科发表《中华人民共和国 与俄罗斯联邦关于丝绸之路经济带建设和欧亚经 济联盟建设对接合作的联合声明》,指出未来中俄 将在投资贸易、产能合作、基础设施、自贸区建设、 金融等 8 个领域加强合作 ${ }^{[33]}$ 。2016 年 6 月, 中蒙俄 三国签署《建设中蒙俄经济走廊规划纲要》,明确指 出要加强三方在能源矿产资源、高技术、制造业和 农林牧等领域合作 ${ }^{[3]}$ 。中俄区域发展政策高度契 合, 双方合作意愿强烈, 能源合作作为中俄的重点 合作领域,无疑将迎来新的发展机遇。

（5）地理优势明显,有助于降低成本和运输风 险。中俄互为近邻, 拥有 $4300 \mathrm{~km}$ 的国境线, 两国之 间可以直线建设油气管道、输送油气资源, 能够有 效地降低建设成本和运输成本。另外,油气运输不 
需经转第三国, 可以极大地降低运输风险, 保障运 输安全,这是中东、西非、欧洲地区所不可比拟的。

\subsection{2 外部推动因素}

中俄利益诉求的内在契合性是中俄开展能源 合作的决定性因素，而欧盟能源政策调整、页岩气 革命、乌克兰变局等国际地缘环境变迁的外部因素 则推动了中俄能源合作的进程。

(1) 欧盟能源供应多元化战略。俄罗斯是欧盟 主要的能源供应地, 2013 年, 欧盟从俄罗斯进口的 天然气占欧盟天然气进口总量的 $33 \%{ }^{[34]}$, 受地缘政 治的影响, 俄欧长期以来一直处于能源博弯状态, 欧盟担心俄罗斯打能源外交牌，以实现其政治目 的。因此,实现能源供应多元化是欧盟重要的能源 战略目标, 而该目标在欧盟经历过俄罗斯三次断供 之后 (俄罗斯于 2006 年、2009年、2014年三次中断 对欧洲和乌克兰的天然气供应) 显得更加紧迫。为 了降低对俄罗斯能源供应的依赖,2008年欧盟委员 会开始规划 “南方天然气走廊”, 意图绕开俄罗斯从 中东和里海沿岸国家进口天然气。2014年9月 “南 方天然气走廊”正式开建, 建成后加上已启用的巴 杰(BTC) 输油管道, 将成功地绕开俄罗斯从里海沿 岸获取油气资源。此外, 欧盟国家加大了对本土能 源的开发, 大力发展可再生能源, 其《2020-2030年 气候和能源政策框架》制定了到 2020 年欧盟范围内 可再生能源至少提高到 $27 \%$ 的约束性目标 ${ }^{[35]}$ 。欧盟 的能源政策使得俄罗斯在欧洲能源市场的前景愈 加暗淡,迫使俄罗斯向东扩展市场。

(2) 美国页岩气革命。美国页岩气革命将通过 以下两方面对俄罗斯能源出口产生影响: (1) 将削弱 俄罗斯把能源作为外交手段的力量, 降低俄罗斯通 过 “能源武器”对国际地缘环境的影响; (2)页岩气的 大规模开发可能导致世界油气市场缩减, 使油气市 场竞争更加激烈, 油气价格下降, 致使俄罗斯油气 出口出现 “量价齐衰” 的态势。从目前油气市场来 看, 西方发达国家油气市场基本饱和, 向东转移成 为油气出口国的重要方向 ${ }^{[34,36]}$ 。

(3) 乌克兰变局。乌克兰变局是中俄能源合作 的重要催化剂。因乌克兰问题, 俄罗斯受到欧美国 家的联合制裁, 能源领域是欧美联合制裁的重点领 域。在西方国家打压和国际油价低迷的双重影响
下,俄罗斯油气出口呈现量价齐衰,严重依赖油气 收人的俄罗斯经济陷人衰退中。为了应对西方国 家的联合打击, 俄罗斯将战略目光向东转移, 将与 中国开展油气合作视为摆脱困境的重要突破口。

(4)中国-中亚天然气合作日渐紧密。中亚地区 天然气资源丰富, 天然气探明储量高达 22 万亿 $\mathrm{m}^{3}$, 占世界天然气探明储量的 $12 \%{ }^{[2]}$ 。中国政府在推动 中俄能源合作的同时,也在积极推动中国-中亚能 源合作。近年来, 中国-中亚能源合作日趋紧密, 中 亚向中国的天然气输送量不断增加,截止 2017 年 6 月,中国-中亚天然气管道累计向中国输气 1841 亿 $\mathrm{m}^{3}$, 未来随着中亚天然气管道 $\mathrm{D}$ 线建成投产, 中亚向中 国的天然气年输送量有望达到 850 亿 $\mathrm{m}^{3[3]}$ 。中亚成 为俄罗斯在中国天然气市场的有力竞争者,这也迫 使俄罗斯调整对华的能源政策。

在中俄政府的推动下,国际地缘环境变迁的影 响下, 中俄多年悬而未果的谈判项目取得重大突 破, 中俄于 2014 年 5 月和 11 月签订《中俄东线供气

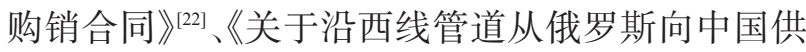
应天然气的框架协议 $\rangle^{[23]}$, 中俄天然气合作进人快 车道。

\section{2 中俄能源合作的挑战}

“内外联动”促使中俄能源合作取得了较大进 展, 然而, 虽目前中俄能源合作态势良好, 但是仍存 在诸多挑战 ${ }^{[9,10,38-40]}$, 主要表现为以下几个方面:

\subsection{1 来自俄罗斯方面的挑战}

(1)俄罗斯“能源外交”导致能源政策缺乏稳定 性。作为能源大国, “能源外交” 是俄罗斯重要的外 交战略手段。为了维护本国利益,俄罗斯把油气供 应作为向其他能源依赖国施加经济与政治压力的 杜杆, 通过能源杜杆制衡他国, 彰显大国地位, 由此 导致俄罗斯能源政策、能源供应缺乏稳定性。

(2) 政治互信不足，“中国威胁论”挥之不去。 中国是新兴大国,经济大国,俄罗斯一方面担心中 国迅速崛起会与自己争夺资源和主导权,制衡并取 代其大国地位,成为牵制俄罗斯在亚太地区乃至全 球的重要力量。另一方面,俄罗斯担心成为中国崛 起的原材料附庸国。虽 “中国威胁论”在中俄全面 战略协作伙伴关系中不占主流,但其若隐若现, 挥 之不去。 
(3)俄罗斯国内投资环境欠佳。俄罗斯能源政 策缺乏稳定性、连续性,尤其是原油、成品油关税、 法律法规频繁修改,大大降低了外国投资者进人俄 罗斯市场的积极性与可能性。同时,能源产业作为 俄罗斯的支柱产业,俄政府加大了对能源产业的国 家控制, 形成了国内几大油气寡头, 同时提高了外 国投资者开发地下资源的准人门槛,严重挫伤外企 投资俄能源领域的积极性。此外,俄罗斯的官僚主 义、腐败问题、各利益集团之间的恶性竞争等也严 重影响了俄罗斯的投资环境。

\subsection{2 来自中国方面的挑战}

(1)中国在国际能源市场的话语权不高, 在国 际能源合作中处于被动地位。中国的油气公司国 际化水平不高,自身实力有限,且在海外投资较晚, 使中国在国际能源竞争和国际能源投资贸易中处 于劣势地位, 在国际能源市场上缺乏话语权。据统 计, 中石油、中海油、中石化的全部资产还不及石油 巨头埃克森美孚资产的 $1 / 3^{[12]}$, 因此, 中国在国际能 源合作中往往受制于发达国家，处于被动地位。

（2）中国缺乏有效的国际能源协调管理机制, 难以及时应对国际能源市场的变化。中国缺乏有 效的国际能源协调管理机制, 缺乏长期、系统的能 源战略规划, 导致中国对世界能源战略了解欠缺, 难以对瞬息万变的油气市场做出准确判断和应对 决策,这在一定程度上制约了中俄能源合作的进程。

\subsection{3 来自中俄双方共同的挑战}

(1)中俄能源合作缺乏基于顶层设计的能源合 作长期规划与机制。中俄能源合作缺乏基于顶层 设计的、长期的 “能源合作战略性文件”, 使中俄能 源合作容易受到外部因素扰动。中俄政府应充分 认识到中俄能源合作的战略意义, 联合制定中俄能 源合作的战略性、纲领性文件, 从国家层面引领、推 进、保障中俄能源合作。

此外,中俄能源合作缺乏完善的合作机制。主 要表现为: (1)中国的权益易受威胁。目前中俄油气合 作主要以中国“预付款”、“石油换贷款”的形式进行, 这使中国处于被动地位,自身权益难以保证;(2) 面临 国际地缘环境、油气市场的波动, 中俄缺乏相应的 保障机制以应对危机，从而对两国权益带来挑战。

(2) 中俄能源合作面临他国的激烈竞争。美、
日是中俄能源合作的最大竞争者。对于美国而言, 俄罗斯一直在其全球能源战略中处于重要地位, 美 国担心中俄能源的紧密合作会对其全球能源战略 带来挑战,降低其对中国能源市场的影响。对于日 本而言, 日本能源极度匮乏, 对中东地区石油依赖 程度高, 日俄能源合作同样是其能源进口多元化、 保障能源安全的重要战略。因此,多年来, 日本与 中国在与俄罗斯能源合作方面竞争激烈。此外,韩 国以及经济快速发展的印度也成为中俄能源合作 的有力竞争者。

\section{4 深化中俄能源合作的对策}

中俄能源合作既是经贸合作, 又是保障两国能 源安全的地缘战略合作，同时也将对世界能源格 局、地缘政治格局产生重大影响。面对日益复杂的 国际环境, 为保障两国的能源安全, 中俄应增强互 信、深化合作、抓住机遇、克服挑战 ${ }^{[6-12,38,39,41-44]}$, 依托 “一带一路”倡议、“中蒙俄经济走廊”建设和“欧亚 经济联盟”建设, 不断深化中俄关系, 稳步推进中俄 能源合作。

\section{1 增强政治互信, 深化中俄能源地缘战略合作}

中俄能源合作不仅仅是经贸合作,更是保障两 国能源安全、应对外部压力的地缘战略合作。然 而, 受“中国威胁论”的影响, 俄罗斯部分人士对中 俄能源合作存有疑虑, 俄罗斯一些人士担心中国的 崛起会成为牵制俄罗斯重返大国新的力量, 威胁其 在亚太的地位。对此, 两国应加强互信互利建设, 充分认识到两国在经济、政治等方面利益诉求的一 致性, 以共同的利益诉求为准则, 加强两国全面战 略协作伙伴关系,深化中俄能源的地缘战略合作。 中方应加强对俄罗斯基本国情、利益诉求、能源政 策、投资环境、民族文化等方面的研究，同时加大对 中国正面国际形象的宣传,不断拓展交往方式,实 现从首脑外交到民间交流、从政治交往到文化交 往、学术交往、人才交往等的多方位交流与合作,增 加俄罗斯对中国国情、中国文化的了解, 增信释疑, 消除俄罗斯对中国的偏见和顾虑。

\section{2 抓住政策机遇,拓宽合作模式与合作领域}

2016年6月,中蒙俄三国首脑签署《建设中蒙俄 经济走廊规划纲要》,指出要“加强三方在能源矿产 资源、高技术、制造业和农林牧等领域合作” ${ }^{\left[{ }^{3]}\right.}$, 为中 
俄能源合作带来了新机遇。在中蒙俄经济走廊建 设背景下, 中俄应抓住机遇, 不断完善合作模式与 合作领域, 深化中俄能源合作。虽中俄能源合作已 逐渐由油气贸易向全产业链扩展, 但贸易占主导地 位的状态并未得到根本改变, 且油气贸易大多通过 预付款的方式进行, 使中国处于被动地位, 权益难 以保障。因此,中国必须大力推进 “走出去”战略, 拓宽能源合作模式与合作领域, 在坚持能源地缘战 略合作的前提下, 加快推进市场主导的合作模式， 通过持股、并购、购买区块、合资建厂等方式深化双 方在油气田勘探、技术服务、炼化、装备等油气全产 业链的合作。

\section{3 制定中俄能源战略长期合作规划, 完善中俄能 源合作机制}

能源合作是中俄的地缘战略合作, 中俄应立足 长远, 加强能源合作的顶层设计与规划, 本着 “互利 共赢” 的原则, 借助已建立的对话机制, 依托上海合 作组织, 制定中俄能源战略长期合作规划, 构建中 俄能源合作机制, 完善中俄能源定价机制和能源合 作风险防控机制, 有效防控、规避在合作中出现的 市场、价格、汇率、政策、法律变动等风险。

\section{4 兼顾周边地区, 创建区域性能源共同体}

中国、日本、韩国、印度等都是能源稀缺国, 从 地缘政治、地理位置、运输安全、能源政策等角度来 讲,均对与俄罗斯开展能源合作具有强烈需求,因 此,中俄能源合作面临激烈的国际竞争, 本世纪初 的中日俄石油管线之争就是最好的例子。然而, 能 源安全并非一国所能解决, 对于东北亚地区而言, 能源是一把双刃剑, 一方面可能造成大国对抗加剧 地区紧张, 另一方面通过恰当的合作模式, 可以化 解国家之间的矛盾 ${ }^{[1]}$ 。因此, 在中俄双边能源合作 稳定的基础上,中俄能源合作应该兼顾周边地区， 协调各方利益需求,探索创建区域性的能源共同 体,避免恶性竞争, 这对提高亚太地区的稳定性以 及中俄能源合作的稳定性具有重要的建设性作用。

\section{参考文献(References):}

[1] 孙龙德, 钱兴坤, 姜雪峰, 等. 中俄油气合作 20 年[J]. 国际石油 经济, 2015, 23(11): 1-9. [Sun L D, Qian X K, Jiang X F, et al. Oil and gas cooperation between China and Russia for 20 years[J]. International Petroleum Economics, 2015, 23(11): 1-9. ]

[2] 郝宇彪, 田春生. 中俄能源合作: 进展、动因及影响[J]. 东北亚 论坛, 2014, (5): 71-83. [Hao Y B, Tian C S. Sino Russian energy cooperation: Progress, motivation and influence [J]. North East Asia Forum, 2014, (5): 71-83. ]

[3] 国家发改委. 中蒙俄经济走廊规划纲要[EB/OL]. (2016-09-14) [2017-03-04]. http://www.scio.gov.cn/ztk/wh/slxy/htws/Document/ 1491208/1491208.htm. [National Development and Reform Commission. Plan for Construction of the China-Mongolia-Russia Economic Corridor [EB/OL]. (2016-09-14)[2017-03-04]. http://www. scio.gov.cn/ztk/wh/slxy/htws/Document/1491208/1491208.htm. ]

[4] 徐洪峰, 施佳敏. 中俄能源合作综述[J]. 俄罗斯学刊, 2014, (6): 85-92. [Xu H F, Shi J M. Sino Russian energy cooperation[J]. Academic Journal of Russian Studies, 2014, (6): 85-92. ]

[5] 陈小沈. 上海合作组织框架内的中俄能源利益分析[J]. 国际关 系学院学报, 2011, (5): 89-94. [Chen X Q. The interests' analysis of Sino Russian energy within the framework of the Shanghai cooperation organization [J]. Journal of University of International Relations, 2011, (5): 89-94. ]

[6]陈宪良. 中国能源安全与中俄能源合作[J]. 东北亚论坛, 2017, (3): 59-73. [Chen X L. China's energy security and Sino-Russian energy cooperation [J]. Northeast Asia Forum, 2017, (3): 59-73. ]

[7] 郭锐, 洪英莲. 中俄能源合作的问题与对策 [J]. 经济纵横, 2009, (9): 40-43. [Guo R, Hong Y L. Problems and suggestions of Sino Russian energy cooperation [J]. Economic Review, 2009, (9): 40-43. ]

[8] 张恒龙, 秦鹏亮. 中俄能源合作博峦及其地缘政治经济影响 [J]. 上海大学学报(社会科学版), 2015, 32(1): 32-44. [Zhang H L, Qin P L. The game in Sino-Russian energy cooperation and its influence on geopolitics and economics [J]. Journal of Shanghai University (Social Sciences), 2015, 32(1): 32-44. ]

[9] 王海运. 中俄能源合作的有利因素与制约因素 [J]. 俄罗斯学 刊, 2011, 1(3): 5-9. [Wang H Y. Favorable factors and restraints in Sino-Russian energy cooperation[J]. Academic Journal of Russian Studies, 2011, 1(3): 5-9. ]

[10] 朗一环, 王礼茂. 俄罗斯能源地缘政治战略及中俄能源合作前 景[J]. 资源科学, 2007, 29(5): 201-206. [Lang Y H, Wang L M. Russian energy geopolitic strategy and the prospects of Sino-Russia energy cooperation[J]. Resources Science, 2007, 29(5): 201206. ]

[11] 方婷婷. 俄罗斯对外能源战略和中俄能源博弯[J]. 东北亚论坛, 2012, 21(3): 36-43. [Fang T T. Russia foreign energy strategy and Sino-Russian energy game [J]. Northeast Asia Forum, 2012, 21(3): 36-43. ]

[12] 方婷婷. 中俄能源合作: 影响因素与现实选择[J]. 当地世界与社 会主义, 2011, (3): 88-91. [Fang T T. Sino Russian energy cooper- 
ation: influence factors and practical choice [J]. Contemporary World and Socialism, 2011, (3): 88-91. ]

[13] 陈小沁. 解析《2030 年前俄罗斯能源战略》[J]. 国际石油经济, 2010, (10): 41-48. [Chen X Q. Analysis of Russia's energy strategy to 2030[J]. International Petroleum Economics, 2010, (10): 4148. ]

[14] 王晓梅. 俄罗斯能源战略调整与中俄能源合作 $[J]$. 国际经济合 作, 2015, (4): 64-68. [Wang X M. Adjustment of Russian energy strategy and Sino-Russian energy cooperation [J]. Journal of International Economic Cooperation, 2015, (4): 64-68. ]

[15] United Nations. UN Comtrade Database [EB/OL]. (2017-02-04) [2017-02-05]. https: //comtrade.un.org/data/.

[16] 中国国土资源报. 中俄油气合作大事记[EB/OL]. (2014-05-28) [2017-03-05]. http://www.gtzyb.com/guojizaixian/20140528_65264. shtml. [China National Land Resource Newspaper. A Memorabilia of Sino Russian Oil and Gas Cooperation [EB/OL]. (2014-05-28)[201703-05]. http: //www.gtzyb.com/guojizaixian/20140528_65264.shtml. ]

[17] 安蓓. 中石油宣布出资 5 亿美元购买俄罗斯石油公司上市股票 [EB/OL]. (2006-07-19)[2017-03-05]. http: //www.china.com.cn/ txt/2006-07/19/content_7014203.htm. [An B. CNPC Announced $\$ 500$ Million for the Purchase of Russian Oil Companies [EB/OL]. (2006-07-19)[2017-03-05]. http: //www.china.com.cn/txt/200607/19/content_7014203.htm.]

[18] 闻育旻. 中俄签石油领域合作协议, 能源合作实现重大突破 [EB/OL]. (2009- 04- 21) [2017-03-05]. http: //www.chinanews. com/cj/kong/news/2009/04-21/1656410.shtml. [Min Y M. China and Russia Have Signed a Cooperation Agreement in the Field of Oil, Which Is a Major Breakthrough in Energy Cooperation [EB/ OL]. (2009-04-21)[2017-03-05]. http: //www.chinanews.com/cj/ kong/news/2009/04-21/1656410.shtml. ]

[19] 安蓓, 朱诸. 中俄签署通过东线管道向中国供应天然气框架协 议[EB/OL]. (2013-09-06)[2017-03-05]. http: //finance.sina.com. cn/world/20131023/155717086425.shtml. [An B, Zhu Z. China and Russia Signed an Agreement on the Supply of Natural Gas to China through the East Pipeline [EB/OL]. (2013-09-06) [201703-05]. http: //finance.sina.com.cn/world/20131023/155717086425. shtml. ]

[20] 朱诸, 安蓓. 中石化和俄石油签署预付款出口合同备忘录[EB/ OL]. (2013-09-06)[2017-03-05]. http: //www.gov.cn/jrzg/201309/06/content_2482824.htm. [Zhu Z, An B. Sinopec and Rosneft Oil Signed a Memorandum of Prepaid Export Contract [EB/OL]. (2013-09-06)[2017-03-05]. http: //www.gov.cn/jrzg/2013-09/06/ content_2482824.htm.]

[21] 吕思言. “两桶油”与俄签油气协议, 每年进口 1000 万吨原油 [EB/OL]. (2013- 10- 24) [2017-03-05]. http: //www.chinanews. com/ny/2013/10-24/5417242.shtml. [Lv S Y. CNPC and Sinopec Signed Oil and Gas Agreements with Russia, Import 10 Million
Tons of Crude Oil Each Year [EB/OL]. (2013-10-24)[2017-0305]. http: //www.chinanews.com/ny/2013/10-24/5417242.shtml. ]

[22] 杜燕飞, 王静. 中俄签署东线管道供气购销合同, 年供气 380 亿 立方米[EB/OL]. (2014-05-23)[2017-03-05]. http: //energy.people.com.cn/n/2014/0523/c71890-25056648.html. [Du Y F, Wang J. China and Russia Signed Supply and Marketing Contract of the East Pipeline, 38 Billion Cubic Meters of Gas Will Be Supplied Per Year [EB/OL]. (2014-05-23) [2017-03-05]. http: //energy. people.com.cn/n/2014/0523/c71890-25056648.html. ]

[23] 新京报. 习近平会晤普京, 中俄签西线天然气协议[EB/OL]. (2014-11-10) [2017-03-05]. http: //epaper.bjnews.com.cn/html/ 2014-11/10/content_545239.htm?div=-1. [The Beijing News. Xi J P met Putin V, China and Russia Signed the Agreement of West Gas Pipeline [EB/OL]. (2014-11-10)[2017-03-05]. http: //epaper. bjnews.com.cn/html/2014-11/10/content_545239.htm?div=-1. ]

[24] 戚伟. 中俄东线天然气管道 2018 年底通气[EB/OL]. (2015-1218) [2017-03-05]. http: //news.xinhuanet.com/finance/2015-12/ 18/c_128545722.htm. [Qi W. China and Russia Eastern Gas Pipeline Will Be in Application in 2018[EB/OL]. (2015-12-18)[201703-05]. http: //news.xinhuanet.com/finance/2015-12/18/c_128545722. htm. ]

[25] BP. Statistical Review of World Energy 2016[EB/OL]. (2016-0609) [2017- 02- 05]. http: //www.bp.com/dam/bp/en/corporate/pdf/ energy-economics/statistical-review-2016/bp-statistical-reviewof-world-energy-2016-full-report.pdf.

[26] 安菩. 中石化收购俄西布尔公司 $10 \%$ 股权完成交割 $[\mathrm{EB} / \mathrm{OL}]$. (2015-12-18) [2017-03-05]. http: //news.xinhuanet.com/201512/18/c_1117499518.htm. [An B. Sinopec Has Completed the Process of Purchasing 10\%'s Stake in Sibur [EB/OL]. (2015-12-18)[201703-05]. http: //news.xinhuanet.com/2015-12/18/c_1117499518.htm. ]

[27] 孙贤胜, 钱兴坤, 姜学峰, 等. 2015 年国内外油气行业发展报告 [M]. 北京: 石油工业出版社, 2016. [Sun X S, Qian X K, Jiang X F, et al. 2015 Domestic and International Oil and Gas Industry Development Report [M]. Beijing: Petroleum Industry Press, 2016. ]

[28] U. S. Energy Information Administration. International Energy Outlook 2014 [EB/OL]. (2014-09-22)[2017-02-06]. https: //www.eia. gov/pressroom/presentations/sieminski_09222014_columbia.pdf.

[29] 国务院. 能源发展战略行动计划(2014-2020年)[EB/OL]. (201412- 03) [2017-03-05]. http: //www.nea.gov.cn/2014- 12/03/c_ 133830458.htm. [The State Council. Strategic Action Plan for Energy Development (2014-2020) [EB/OL]. (2014-12-03) [201703-05]. http: //www.nea.gov.cn/2014-12/03/c_133830458.htm. ]

[30] 俄罗斯能源部. 2030 年前俄罗斯能源战略[EB/OL]. (2009-1113) [2017-02-06]. http: //government.ru/.[Russian Energy Ministry. The Energy Strategy until 2030[EB/OL]. (2009-11-13)[201702-06]. http: //government.ru/. ]

[31] 俄罗斯能源部. 2035 年前俄罗斯能源战略草案[EB/OL]. (2014- 
02- 19) [2017- 02- 06]. http: //government.zu/.[Russian Energy Ministry. The Draft Energy Strategy until 2035[EB/OL]. (201402-19)[2017-02-06]. http: //government.ru/. ]

[32] Giffi C A, Roth A V, Rodriguez M D, et al. 2016 Global Manufacturing Competitiveness Index[EB/OL]. (2016-04-06) [2017-0206]. https: //www2.deloitte.com/global/en/pages/manufacturing/articles/global-manufacturing-competitiveness-index.html.

[33] 新华网. 中华人民共和国与俄罗斯联邦关于丝绸之路经济带建 设和欧亚经济联盟建设对接合作的联合声明[EB/OL]. (201505-08)[2017-03-05]. http: //news.xinhuanet.com/world/2015-05/ 09/c_127780866.htm. [Xinhua Net. The Joint Statement by the People's Republic of China and the Russian Federation on the Construction of Silk Road Economic Belt and Eurasian Economic Union[EB/OL]. (2015-05-08)[2017-03-05]. http: //news.xinhuanet.com/world/2015-05/09/c_127780866.htm. ]

[34] 程卫东. 欧盟能源供应安全的国际战略及其困境[J]. 欧洲研究, 2015, (3): 15-27. [Cheng W D. EU's international strategy for energy supply security and its dilemma [J]. Chinese Journal of European Studies, 2015, (3): 15-27. ]

[35] European Commission. A Policy Framework for Climate and Energy in the Period from 2020 to 2030[EB/OL]. (2014-01-22)[2017/02- 06]. http: //eur- lex.europa.eu/legal- content/EN/TXT/PDF/? uri=CELEX: 52014DC0015\&from=EN.

[36] 李昕. 中俄油气合作新发展的特征、动因及影响探析[J]. 国际论 坛, 2016, 18(1): 33-41. [Li X. Analysis on the characteristics, causes and influence of Sino Russian oil and gas cooperation [J]. International Forum, 2016, 18(1): 33-41. ]

[37] 王卫国. 中亚天然气管道未来有望每年向中国输气 850 亿立方 米[N]. 南方都市报, 2017-07-15(05). [Wang W G. The Central Asian Natural Gas Pipeline Is Expected to Transport 85 Billion $\mathrm{m}^{3}$ Gas per Year to China in the Future [N]. Southern Metropolis Dai- ly, 2017-07-15(05). ]

[38] 陈柳钦. 中俄油气合作需要舒缓瓶颈[N]. 中国能源报, 201310-14(11). [Chen L Q. Sino Russian Oil and Gas Cooperation Needs to Ease the Bottleneck [N]. China Energy News, 2013-1014(11). ]

[39] 赵先良, 潘继平. 中俄油气合作重大进展及其潜在风险与对策 [J]. 国际石油经济, 2014, 22(10): 29-33. [Zhao X L, Pan J P. Significant progress, potential risks and mitigation in Sino-Russian oil and gas cooperation[J]. International Petroleum Economics, 2014, 22(10): 29-33. ]

[40] 赵庆寺. 国际合作与中国能源博峦[J]. 江西社会科学, 2007, (6): 122-128. [Zhao Q S. International cooperation and energy game in China[J]. Jiangxi Social Sciences, 2007, (6): 122-128. ]

[41] 董锁成, 黄永斌, 李泽红, 等. 丝绸之路经济带经济发展格局与 区域经济一体化模式[J]. 资源科学, 2014, 36(12): 2451-2458. [Dong S C, Huang Y B, Li Z H, et al. Economic development patterns and regional economic integration modes for the silk road economic zone[J]. Resources Sciences, 2014, 36(12): 2451-2458. ]

[42] 于会录, 董锁成, 李宇, 等. 丝绸之路经济带资源格局与合作开 发模式研究[J. 资源科学, 2014, 36(12): 2468-2475. [Yu H L, Dong S C, Li Y, et al. Resource cooperation development modes in the silk road economic zone based on resource distribution patterns [J]. Resources Sciences, 2014, 36(12): 2468-2475]

[43] 吕松泽. 中俄能源合作现状分析及对策研究[J]. 黑龙江对外经 贸, 2007, (9): 9-13. [Lv S Z. Analysis and countermeasures of Sino Russian energy cooperation[J]. HLJ Foreign Economic Relations \&Trade, 2007, (9): 9-13. ]

[44] 庞昌伟. 俄罗斯油气资源及中俄油气合作[J]. 俄罗斯学刊, 2013, (4): 5-12. [Pang C W. Russian oil and gas resources and the Sino-Russian oil and gas resources cooperation[J]. Academic Journal of Russian Studies, 2013, (4): 5-12. ] 


\title{
Progress, driving forces and challenges of Sino-Russian energy cooperation under the China-Mongolia-Russia economic corridor
}

\author{
YANG Yang ${ }^{1,2}$, DONG Suocheng ${ }^{1,2}$, LI Zehong ${ }^{1,2}$ \\ (1. Institute of Geographic Sciences and Natural Resources Research, Chinese Academy of Sciences, Beijing 100101, China; \\ 2. University of Chinese Academy of Sciences, Beijing 100049, China)
}

\begin{abstract}
Sino- Russian energy cooperation is geo- strategic cooperation between China and Russia, and is an important part of the China- Russia comprehensive strategic partnership of coordination. Since 1996 when Sino-Russian energy cooperation started, it has undergone many setbacks, but also great progress. Cooperation fields have expanded from the oil and gas trade to whole industry chain cooperation including oil and gas exploration and development, technical services of upstream cooperation, oil and gas pipeline construction of midstream cooperation, refining and chemical cooperation of downstream cooperation, along with implementation of the China- Mongolia- Russia Economic Corridor, Sino- Russian energy cooperation embraces new opportunities. We summarized progress in Sino-Russian energy cooperation, analyzed internal and external driving forces of energy cooperation from the perspectives of supply and demand, energy policy, international division of labor, comparative advantages and international geo-environment change. We concluded that energy supply and demand and comparative advantages between China and Russia are highly complementary, energy strategies and regional development strategies are highly consistent, and geographic advantages are obvious. The internal consistency of SinoRussian interests determine the necessity to launch Sino- Russian oil and gas cooperation, while external factors such as adjustment of the European union's energy strategy, shale gas revolution, the Ukraine event in 2014, increasing close energy cooperation between China and Central Asia, accelerated the process of Sino-Russian oil and gas cooperation. Though current Sino-Russian oil and gas cooperation is promising, there are still many challenges. With the increasingly complex international geo- environment, to promote Sino- Russian energy cooperation, Russia and China should strengthen mutual trust, improve Sino- Russian geo- strategic cooperation; fully take advantage of strategic opportunities arising from the China-Mongolia-Russia Economic Corridor, extend cooperation modes and fields; establish long- term Sino Russian energy cooperation strategic plans; improve Sino- Russian energy cooperation mechanisms; and together with surrounding countries establish a regional energy community.
\end{abstract}

Key words: Sino-Russion energy cooperation; progress; driving forces; challenges; strategies; China-Mongolia-Russia economic corridor 